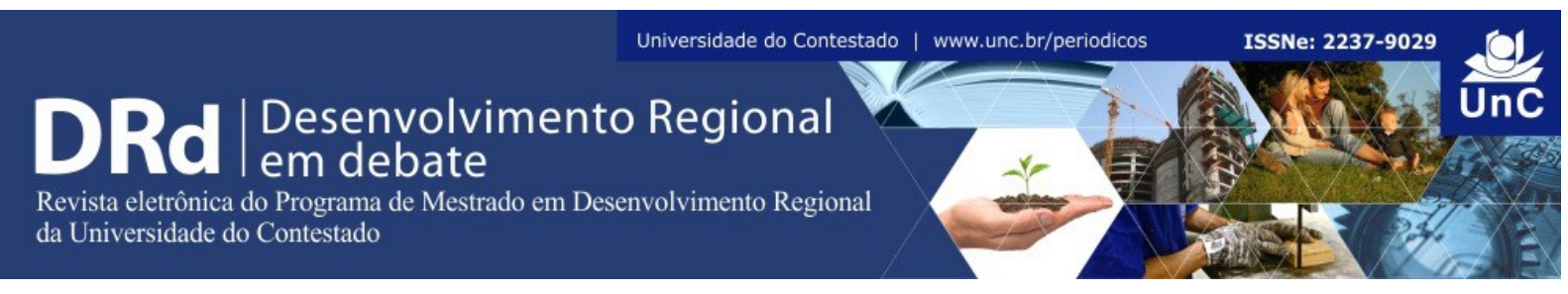

\title{
EMPREGO FORMAL AGROPECUÁRIO E SALDO DE VAGAS NA MICRORREGIÃO DO CARIRI CEARENSE
}

\author{
Fládia Valéria Dantas dos Santos ${ }^{1}$ \\ Paulo Victor Maciel da Costa ${ }^{2}$ \\ Maria Messias Ferreira de Lima $^{3}$ \\ Luís Abel da Silva Filho ${ }^{4}$
}

\begin{abstract}
RESUMO
$\mathrm{O}$ artigo tem como objetivo analisar o saldo de vagas nos postos de trabalho formais da microrregião do Cariri cearense, segundo as características demográficas e socioeconômicas dos trabalhadores, nos anos de 2006 e 2013. Metodologicamente, utiliza-se o método de cálculo da Taxa de Criação Líquida (TCL) de empregos formais, construído com dados do Ministério do Trabalho (MTE) - Relação Anual de Informações Sociais (RAIS) e Cadastro Geral de Empregados e Desempregados (CAGED). Os principais resultados mostraram o aumento na geração de trabalhos formais na agropecuária da microrregião do Cariri; o pequeno estabelecimento demonstrou TCL superior aos demais; o trabalhador do sexo masculino manteve taxa superior a do sexo feminino; viu-se maior TCL na faixa etária de 40 a 49 em 2006, e de 50 a 59 em 2013; prevaleceu com maior TCL a faixa de menor nível de escolaridade; e, quanto a remuneração, a maior TCL corresponde a faixa de até 1 salário mínimo.
\end{abstract}

Palavras-chave: Modernização. Agropecuária. Mercado de trabalho.

\footnotetext{
${ }^{1}$ Mestrado em Economia pela Universidade Federal do Espírito Santo (UFES) e Graduação em Economia pela Universidade Regional do Cariri - URCA. Vitória. Espírito Santo. Brasil. E-mail: fladiavaleria@hotmail.com ${ }^{2}$ Mestrando no Programa de Pós-Graduação em Demografia (PPGDem) da Universidade Federal do Rio Grande do Norte (UFRN), pesquisador do Observatório das Migrações no Estado do Ceará (OMEC/CNPQ). Natal. Rio Grande do Norte. Brasil. E-mail: paulovisctorma22@hotmail.com

${ }^{3}$ Graduação em Economia e Mestrado em Economia Rural, Doutoranda em Geografia pela Universidade Federal da Paraíba - UFPB. João Pessoa. Paraíba. Brasil. E-mail: mefeli@bol.com.br

${ }^{4}$ Doutorado em Ciências Econômicas pelo Instituto de Economia da Universidade Estadual de Campinas UNICAMP. Professor do Departamento de Economia da Universidade Regional do Cariri - URCA. Crato. Ceará. Brasil. E-mail: abeleconomia@hotmail.com
} 


\title{
FORMAL AGRICULTURAL EMPLOYMENT AND BALANCE OF VACANCIES IN THE MICRO REGION OF CARIRI CEARENSE
}

\begin{abstract}
The article aims to analyze the balance of vacancies in the formal jobs of the micro region of Cariri Cearense, according to the demographic and socioeconomic characteristics of the workers, in the years of 2006 and 2013. Methodologically, the method of calculation of the Rate of Creation Net Employment Survey (TCL), built with data from the Ministry of Labor (MTE) - Annual Social Information Report (RAIS) and General Register of Employed and Unemployed (CAGED). The main results showed the increase in the generation of formal jobs in the agriculture of the Cariri microregion; the small establishment showed TCL higher than the others; the male worker maintained a higher rate than the female; there was a higher TCL in the age group from 40 to 49 in 2006, and from 50 to 59 in 2013; the lowest level of schooling prevailed with the highest LCI; and, in terms of remuneration, the highest TCL corresponds to a range of up to 1 minimum wage.
\end{abstract}

Keywords: Modernization. Agropecuária. Labor market.

\section{INTRODUÇÃO}

O estudo do desenvolvimento rural aponta para alterações expressivas no meio rural brasileiro (GRAZIANO DA SILVA, 1997; GIRARD, 2005). O avanço da fronteira agrícola, a introdução de tecnologias de ponta, a abertura comercial, a competição e o processo de urbanização podem ser exemplos dessas novas características (CAMPOLINA et al., 2008). Porém, de acordo com Kageyama (2004), o aspecto mais importante da análise do desenvolvimento rural parte do mercado de trabalho. De um lado, porque o trabalho é a fonte de renda, e de outro, porque, de acordo com o curso das mudanças do desenvolvimento, o mercado de trabalho pode ser afetado em quantidade e qualidade.

Nesse sentindo, é importante destacar o processo de modernização vivenciado pela agropecuária brasileira: ela foi a responsável pela intensa eliminação de postos de trabalho no meio rural, graças ao uso de tecnologias poupadoras de mão de obra e, adicionalmente, à demanda por um profissional com novo perfil. Ou seja, a mão de obra com maior nível de qualificação (FERREIRA et al., 2006, CAMPOLINA et al., 2009; OLIVEIRA, 2010; BALSADI, 2009).

Sob a égide do processo de modernização, as décadas de 70 e 80 foram caracterizadas pela expulsão do homem do campo (DEL GROSSI, 2008; CARNEIRO, 1982). Já a atual dinâmica do meio rural mostra a integração do meio rural com o urbano, assim como a integração do mercado de trabalho. Assim é comum se veem trabalhadores do campo desenvolvendo atividades nas cidades, assim como trabalhadores da cidade sendo atraídos pelas oportunidades de emprego no campo (CAMPOLINA et al., 2009).

Tal é a nova característica que identifica no desenvolvimento do meio rural a presença de atividades não agrícolas, que vêm retendo a população no campo, e, assim, cooperando

DRd - Desenvolvimento Regional em debate (ISSNe 2237-9029) 
para o aumento no nível de renda e consequentemente para a redução da pobreza rural (GRAZIANO DA SILVA, 1997; CAMPOLINA et al., 2009), além da maior participação das políticas públicas, seja por meio da expansão das aposentadorias rurais , seja pelas transferências de renda a partir de programas governamentais implementados (KAGEYAMA, 2003; FERREIRA et al., 2006) e, até mesmo, pelo aumento da formalização das relações de trabalho e pela valorização do salário mínimo (CAMPOLINA et al., 2009).

Porém, no que se referem à agropecuária, estudos como os de Sakamoto e Maia (2012) e Silva Filho e Silva (2011) ainda apontam para a precariedade dos postos de trabalho na agricultura brasileira, decorrente das baixas remunerações, da elevada sazonalidade, do baixo grau de formalização e do baixo nível de escolaridade. Acrescente-se ainda o estudo de Balsadi (2008), segundo o qual os resultados acenam para a desigualdade na qualidade do emprego, com variações de acordo com as regiões do país, entre os trabalhadores rurais e urbanos, os permanentes e temporários, e as culturas praticadas no país.

No Nordeste, apesar de seu destaque na maior participação de contingente rural, a região ainda é caracterizada pela baixa produtividade e baixas remunerações (SAKAMOTO; MAIA, 2012). No âmbito cearense não é diferente.

Porém, no tangente ao emprego formal, o estudo de Santos et al. (2013) para os anos de 2000 e 2010, denotam para a precariedade do emprego. Ao aplicar a metodologia do Índice de Participação Relativa (IPR), os resultados confirmaram o baixo nível de instrução dos trabalhadores, a elevada sazonalidade dos postos de trabalhos e as baixas remunerações auferidas, acompanhando desse modo a dinâmica do perfil de trabalhador nordestino.

Diante das novas características do meio rural brasileiro, o presente artigo tem como objetivo analisar o saldo de vagas nos postos de trabalho formais da microrregião do Cariri cearense, segundo as características demográficas e socioeconômicas dos trabalhadores, nos anos de 2006 e 2013. Metodologicamente, utiliza-se o método de cálculo da Taxa de Criação Líquida (TCL) de empregos formais, construído com dados do Ministério do Trabalho (MTE) - Relação Anual de Informações Sociais (RAIS) e Cadastro Geral de Empregados e Desempregados (CAGED).

O trabalho encontra-se estruturado da seguinte forma: além da introdução, a segunda seção traz uma revisão da literatura teórica sobre mercado de trabalho no campo; na terceira seção apresenta-se os procedimentos metodológicos; em seguida é realizado uma abordagem do desenvolvimento rural e do emprego agropecuário no Brasil e no Ceará; na quinta seção analisaram-se as estatísticas do mercado de trabalho agropecuário na microrregião do Cariri cearense; na sexta seção apresentam-se as taxas de criação e destruição do emprego formal agropecuário na microrregião do Cariri de acordo com as características demográficas e socioeconômicas dos trabalhadores; e, por último, as considerações finais.

\section{REVISÃO TEÓRICA SOBRE O MERCADO DE TRABALHO NO CAMPO}

Martin (1977), buscando compreender as possíveis causas para o emprego/desemprego rural nos Estados Unidos, elenca uma série de questões relacionadas ao processo de mudanças 
demográficas, bem como o êxodo rural acentuado vivenciado naquele país. Para o autor, as políticas voltadas à manutenção e aproveitamento da força de trabalho rural foram pouco efetivas e o forte movimento migratório provocou uma configuração elevada no emprego rural, dado, sobretudo, pela forma de ingresso e permanência da força de trabalho nas aéreas rurais do país. Assim, a elevada rotatividade e baixa qualificação da força de trabalho caracterizava o emprego rural nos anos de 1960 e 1770.

Os problemas que atingem o desemprego rural nos países em desenvolvimento, também, fazem parte de um processo acentuado de transformação nas estruturas produtivas e no perfil da força de trabalho dessa atividade econômica. No meio rural, a participação de pessoas pobres residentes nessas áreas, ainda, é acentuadamente elevada. O surgimento de atividades não agrícolas e empregos assalariados em áreas urbanizadas são alternativas, frequentemente, encontradas para a população rural reingressar na força de trabalho, diante da queda acentuada de empregos agrícolas. Na Tanzânia, conforme Mduna e Wobst (2004), os principais determinantes à inserção e permanência no emprego rural estão pela ótica da elevação da escolaridade da população residentes em áreas rurais; acesso à terra; oferta de crédito e integração com os mercados consumidores. Esses fatores impactam diretamente na retomada dos empregos rurais e na redução da dependência de ocupação em atividades não agrícolas no campo.

Na China, conforme Sheng (2008), as transformações estruturais na agricultura são responsáveis pela dinâmica mais recente do emprego rural naquele país. As mudanças aceleradas no processo de mecanização da agricultura correspondem a um intenso movimento migratório do campo para a cidade. Nessa conjuntura, os perfis dos postos de trabalhos agrícolas demandam mão de obra mais qualificada e exerce um importante papel sobre a elevação da renda agrícola rural do país. Os melhores níveis de qualificação e um processo acancelado de mecanização, o qual corrobora com a elevação da renda no campo, a partir de mudanças elevadas no processo de produção e de trabalho nas áreas rurais chinesas.

Ao estudar as estratégias cabíveis ao processo de reestruturação e reconfiguração do mercado de trabalho na Europa, especificamente na Romênia, Stanef (2012) sugere políticas ativas à juventude no âmbito urbano e rural, com ênfase as políticas de emprego para a população jovem. Dentro das áreas rurais, a proposta é a elevação de financiamento e políticas de crédito e de aprendizagem; acompanhamento da dinâmica da permanência e da política para a juventude; estratégias de inclusão e permanência da juventude no campo com maior elevação da educação formal, eficiência nos postos de trabalho do setor e maiores retornos efetivos das políticas voltadas ao rural europeu. Assim, a redução do êxodo deve estar associada à geração de empregos rurais com maiores níveis de qualificação e melhores retornos salariais à população.

Essas questões relacionadas ao processo de reestruturação da produção rural, a partir da entronização dos métodos e técnicas de produção mecanizadas, também foram responsáveis pela forte migração rural/urbano no Brasil (SILVA, 1999), como exemplos: o êxodo rural aumentou com o processo de mecanização da agricultura brasileira e as reduções dos postos de trabalho foram substancialmente elevadas (BELICK et al., 2003). Com isso, novas formas de organização da produção no rural brasileiro configuraram o perfil da força de trabalho, ainda, nos anos de 1990 e adentraram os anos 2000 com forte tendência à mecanização e a desocupação agrícolas em áreas rurais (KAGEYAMA, 2004). 
As novas formas de organização da produção no meio rural e as configurações oriundas do processo de mecanização caracterizaram-se pelo aumento da demanda por mão de obra qualificada, para ocupação em atividades agrícolas, e pelo forte processo de rotatividade em postos de trabalhos rurais com perfil de ocupados de baixa qualificação (SILVA FILHO, 2013).

Além de que, essa instabilidade do emprego no campo, no caso brasileiro, levou os pequenos produtores a vender sazonalmente sua força de trabalho em outros estabelecimentos agrícolas, face à insuficiência dos seus meios de produção. Outra importante consequência tem sido a multiplicação do trabalho temporário e a dependência maior de formas esporádicas de trabalho, entre categorias sociais como: boias-frias e familiares não remunerados. Assim, o uso de mecanização aumentou as dispensas de trabalhadores permanentes (BALSAN, 2006).

É importante ressaltar que o processo de modernização trouxe mudanças sobre o emprego agrícola de forma diferenciada, ao afetar algumas regiões mais do que outras. Logo, em áreas mais organizadas e capitalizadas, a instabilidade e exploração no trabalho se distinguem das áreas menos capitalizadas. Adicionalmente, o emprego de mão de obra difere de uma cultura para outra, devido os diferentes ciclos do ano agrícola, pois o processo de modernização não atinge todas as fases do ciclo produtivo (BALSAN, 2006).

No Nordeste, a dinâmica do emprego rural também passou por um forte processo de reestruturação, com elevada rotatividade dos postos de trabalho e com geração de emprego que demandavam cada vez mais mão de obra qualificada para desenvolver atividades na agricultura ou na pecuária. Com isso, o emprego rural mecanizado tem ganhado espaço relativamente, frente às atividades manuais desenvolvidas no campo. Essas mudanças na configuração da produção têm apresentado elevados impactos sobre o emprego. Diante disso, os estudos vêm registrando a incidência de rotatividade cada vez maior da força de trabalho no emprego rural nordestino (SILVA FILHO; SILVA, 2011).

Em síntese, como destaca Mendonça, Ribeiro e Thomaz Junior (2002), a nova dinâmica territorial provocou profundas mudanças nas relações sociais de trabalho no espaço rural, com destaque para a desqualificação, a sub-proletarização e outras formas precarizadas de emprego, além do desemprego e da expulsão (desterritorialização) de milhares de famílias, que passaram a aglomerar-se, precariamente, nos centros urbanos, sendo, esse processo, redefinidor da questão cidade-campo.

\section{PROCEDIMENTOS METODOLÓGICOS}

Este trabalho tem como objetivo analisar a taxa de criação líquida de postos de trabalhos formais na agropecuária a partir de características demográficas e socioeconômicas dos ocupados formais, levando em consideração o debate teórico em torno do processo de modernização do setor, que altera a dinâmica do mercado de trabalho rural.

Para a construção dos indicadores de taxa líquida de empregos formais, recorreu-se ao banco de dados on-line do Ministério do Trabalho (MTE) - a Relação Anual de Informações Sociais (RAIS) e no Cadastro Geral de Empregados e Desempregados (CAGED). O recorte 
temporal é justificado pelas limitações do banco de dados. No caso da RAIS, o último ano disponível é o de 2013; e, a CAGED, só passa a fornecer informações no seu banco de dados on-line a partir do ano de 2006. Tais fatores não permitiram um recorte temporal maior.

A relevância do estudo do emprego formal na agropecuária está na mudança de paradigma em relação à dicotomia campo-cidade e na necessidade de geração de empregos para a PEA rural, contribuindo-se para redução da pobreza e do êxodo das áreas rurais. Para Balsadi (2006), a formalidade é uma das importantes condições para a obtenção de aposentadorias e pensões por partes dos trabalhadores; e, por outro lado, também é importante para a previdência social, devido à expansão da sua base de contribuintes. Além do mais, os benefícios previdenciários têm se constituído em melhoria no bem-estar da população, assim como na dinamização das pequenas economias locais (BALSADI, 2006). Vale ressaltar que, embora não seja predominante, está havendo uma tendência crescente da formalização das relações de trabalho (DEL GROSSI, 2008). O que pode ser confirmado através do estudo de Campolina et al. (2009), cujo os autores obtiveram como resultado o aumento de quase 400 mil empregados com carteira entre os anos de 2002 e 2006, valor esse representativo de $2 / 3$ do aumento da PEA rural no período.

A área de abrangência do estudo refere-se à microrregião do Cariri, a qual faz parte da mesorregião do sul cearense e abrange os municípios de Crato, Juazeiro, Barbalha, Jardim, Missão Velha, Porteiras, Santana do Cariri e Nova Olinda. É importante ressaltar que os municípios inclusos na microrregião do Cariri, assim o foram de acordo com a metodologia do IBGE (IPECE, 2013). A escolha da área de estudo se justifica pela grande extensão de municípios rurais, com características climáticas diferenciadas, que permitem o desenvolvimento rural a partir da geração de empregos e a capacidade da região para desenvolver grandes empreendimentos agropecuários (SANTOS et al., 2013).

A análise empírica da criação e destruição de postos de trabalho formais na agropecuária da microrregião do cariri cearense deveu-se a alguns estudos (CORSEUIL et al., 2002a; 2002b; ORELLANO; PAZELLO, 2006; RIBEIRO, 2001; CACCIAMALI; 1992) sobre a rotatividade, tendo sido utilizadas as metodologias empregadas no aparte desta investigação. Conforme estudos citados, a criação de postos de trabalho em um determinado setor e em um período de tempo assume a seguinte expressão:

$$
J C_{i t}=\sum_{i=1}^{N}\left[\left(\frac{A D_{i t}}{X_{i t 0}+X_{i t 1} / 2}\right) I\left(A D_{i t}>0\right)\right]
$$

Nela, $J C_{i t}=$ taxa de criação de postos de trabalho na agropecuária da microrregião do Cariri cearense; $A D_{i t}=$ número de admitidos no setor e no tempo, respectivamente; $X_{i t 0}+X_{i t 1} / 2=$ média do estoque total de ocupados em $t_{0}$ e $t_{1}$ no setor e no tempo, respectivamente, considerando-se o fluxo e o estoque anual pelas bases de dados da RAIS e do CAGED. Para a criação, tem-se que $A D_{i t}>0$. 
Para o registro da taxa de destruição, utiliza-se a fórmula a seguir discriminada:

$$
J D_{i t}=\sum_{i=1}^{N}\left[\left(\frac{D E_{i t}}{X_{i t 0}+X_{i t 1} / 2}\right) I(D E>0)\right]
$$

$J D_{i t}=$ Assume a taxa de destruição de postos de trabalho se, e somente se, $D E>0$.

Para o registro da taxa de criação líquida, faz-se, pois necessário o uso da seguinte expressão matemática:

$$
N E G_{i t}=\sum_{i=1}^{N}\left[\left(J C_{i t}-J D_{i t}\right) I(N E G>0)\right]
$$

$N E G_{i t}$ é a taxa de criação líquida de postos de trabalho agropecuário na microrregião do Cariri cearense. Se ocorrer que: $N E G>0$, é que houve criação líquida; caso contrário, destruição líquida.

A partir do método exposto, fica, pois, possível observar o comportamento do mercado de trabalho formal agropecuário da microrregião do Cariri cearense, considerando-se as características socioeconômicas e demográficas da forma de trabalho formalmente ocupada e sua possível colaboração nos índices registrados.

\section{CONSIDERAÇÕES SOBRE O DESENVOLVIMENTO RURAL E O EMPREGO AGROPECUÁRIO NO BRASIL E NO CEARÁ}

A agricultura brasileira registrou a forte introdução de modernas tecnologias, estimulada pelo cenário de abertura econômica; ampliação dos mercados internacionais; maior rentabilidade na agricultura; exigência por produtos de maior qualidade; além dos interesses ligados à importância do setor agropecuário na participação do PIB. O resultado desse processo foi a redução da demanda por mão de obra e a exigência de um novo perfil profissional para atuar na agropecuária (BALSADI, 2006). Ainda no contexto da modernização, destaca-se a situação das grandes propriedades (aquelas voltadas ao comércio internacional) que, apesar de não serem predominantes, são as que possuem maior participação na área cultivada e produzida, graças aos elevados índices de modernização e mecanização (BALSADI, 2006). De acordo com as expectativas, são essas propriedades as que mais impactam a redução do emprego de mão de obra em virtude da mecanização e da inovação tecnológica utilizada no plantio e na colheita (BAGOLIN; STULP, 2012). 
Nesse contexto, Balsadi (2006) verificou no Brasil o aumento da área cultivada de culturas com elevado grau de modernização, associado à baixa proporção de absorção de empregos. $\mathrm{O}$ autor destaca que, enquanto a área cultivada com as principais culturas (algodão herbáceo, arroz, banana, borracha, café, cana-de-açúcar, feijão, laranja, mamona, mandioca, milho, soja, sorgo granífero, tomate e trigo) cresceu $12,6 \%$ a.a., o número de empregos cresceu apenas 1.4 \% a.a. Dinâmica semelhante foi encontrada no Rio Grande do Sul no ano de 2006, por Bagolin e Stulp (2012): que culturas como arroz, feijão e soja apresentaram impactos negativos nas ocupações decorrentes do alto nível de mecanização. Sakamoto e Maia (2012) também observaram que setores mais dinâmicos da economia, como soja e cana de açúcar, apesar de expressivo valor agregado, possuem pouca representatividade na geração de empregos no Brasil.

Essa dinâmica é justificada por Oliveira (2010). Segundo ela, em razão da ampliação do uso de tecnologias, novos empregos foram gerados por força crescimento da produção no mercado interno e externo. Esses fatores, porém, foram insuficientes para compensar as vagas de empregos eliminadas pelas mudanças tecnológicas. As novas atividades agrícolas passaram a integrar verdadeiras cadeias produtivas, não apenas em relação às transformações da agroindústria, mas também com referência a serviços pessoais e produtivos, envolvendo os ramos de comunicação, distribuição e embalagens (DEL GROSSI, 2008). Para Del Grossi (2008), a dinâmica na geração de empregos no meio rural parte de impulsos gerados pelos setores urbanos. Assim, o autor destaca que as demandas geradas no contexto urbano são de suma importância para o desenvolvimento rural de uma dada região.

Em função dessa relação do rural com o urbano, Silva (1997) destaca a urbanização do meio rural brasileiro como resultado do processo de industrialização da agricultura e também do transbordamento do mundo urbano para aquele espaço identificado como rural. Assim, o autor aborda a dinâmica do emprego rural e enfatiza que o meio rural não pode ser mais identificado como o agrário, e nem mesmo as ocupações como somente agrícolas. Como exemplo cita a acrescente participação de atividades na prestação de serviços, no comércio e na indústria. Considera também o crescimento das ocupações não agrícolas e a integração dos espaços urbanos e rurais, assim como a integração do mercado de trabalho entre esses dois setores. Campolina et al. (2008) destacam que essa nova dinâmica é o caminho para a redução da pobreza rural e por seguinte, da diminuição da desigualdade social, por força da diversificação das fontes de rendas no campo.

Porém, de acordo com Kageyama (2002), a pluriatividade não foi o suficiente para manter a população no campo. A autora ressalta a importância do meio rural, dos rendimentos provenientes de transferências. Esse fato também é realçado por Campolina et al. (2008). Esses autores observaram o crescimento de outras fontes de renda não provenientes de fonte de trabalho, a saber: aposentadorias e transferências governamentais e interpessoais de renda. Como exemplificação, a autora ressalta a universalização da previdência social junto aos idosos do campo, o crescimento do valor real do salário mínimo e os programas de transferências de renda condicionados. Os autores chamam atenção para o seguinte: esses fatores influenciaram como complemento de renda no meio rural e na redução da pobreza no campo.

A análise do período de 1996-2006 mostra a importância dessas políticas, principalmente para o Nordeste e sua população rural. Embora as últimas décadas se caracterizem pela drástica redução da renda agrícola, esta vem sendo compensada pelo 
aumento das aposentadorias, pensões e pelo crescimento das transferências, inclusive o crescimento real das aposentadorias decorrente das políticas de valorização do salário mínimo a partir da primeira metade da década de 2000 . Soma-se a esse cenário o desenvolvimento da pluriatividade e o crescimento das atividades não agrícolas. Tais fatores, em conjunto, responderam pela ampliação do nível de renda no meio rural, o que significou redução da pobreza e desigualdade de renda nesse setor. Logo, a dinâmica oposta das rendas agrícolas e não agrícolas permitiu a estabilidade de renda no meio rural (CAMPOLINA et al., 2008).

Outro movimento recente no meio rural é o aumento na formalidade do trabalho assalariado. De acordo com os dados da PNAD, Campolina et al. (2008) observaram o aumento, entre 2002 e 2006, de quase 400 mil empregados com carteira, o que representou 2/3 do aumento da PEA rural nesses anos. Como destaca Del Grossi (2008), embora não atinja a maioria dos empregados agrícolas, desde a década de 1990 existe uma tendência à formalização das relações de trabalho, que se mantém neste início de década.

Porém, ao analisarem a própria dinâmica do mercado de trabalho na agropecuária, Sakamoto e Maia (2012) destacam que ainda há grandes problemas a serem enfrentados no país. De acordo com o estudo desses autores, o intenso dinamismo da produção agrícola modificou pouco o mercado de trabalho desse setor: ele ainda se caracterizar pelas baixas remunerações e péssimas condições de trabalho. Ou seja, mesmo diante do processo de mecanização, a mão de obra ainda é pouco qualificada. Há limitado grau de assalariamento, sobretudo do emprego formal, além dos fortes contrastes entre empregos permanentes e temporários, no que concernem às remunerações e acessos aos direitos sociais.

A visão de Sakamoto e Maia (2012) pode ser confirmada nos resultados encontrados no estudo de Silva Filho e Silva (2011) para a agropecuária do Nordeste brasileiro no período de 1999-2009. Os resultados aí apontaram para o expressivo número de trabalhadores nas faixas de baixo nível de escolaridade, elevada sazonalidade e obtenção dos menores salários, esses que refletem o perfil do emprego agropecuário dessa região.

Cabe destacar a situação do Nordeste, que apresenta o maior contingente de população rural do país (SAKAMOTO; MAIA, 2012 e FERREIRA et al., 2006), e, em contrapartida possui as piores condições de emprego na agropecuária (BALSADI, 2008), além, de possuir as menores taxas de produtividade e de rendimentos (SAKAMOTO; MAIA, 2012). Balsadi (2008), ao aplicar a metodologia do Índice de Qualidade do Emprego (IQF) para a agropecuária, verificou que na média a melhor condição de emprego para essa região fica relativamente próxima das piores condições nas demais regiões e culturas do país. $\mathrm{O}$ autor ressalta a necessidade de políticas públicas voltada para a redução das desigualdades regionais. Para Ferreira et al. (2006), é nesse sentido que novamente sobressai a importância das transferências de renda para essa região.

Conforme a literatura aqui apresentada, embora a nova dinâmica do meio rural aponte para melhorarias na qualidade de vida da população através da oportunidade de novas atividades no campo (não agrícola), a crescente pluriatividade e do aumento das rendas provenientes de transferências, do ponto de vista da ótica do mercado de trabalho agropecuário, ainda há grandes desafios a serem superados. 


\section{ESTATÍSTICAS DO MERCADO DE TRABALHO AGROPECUÁRIO NA MICRORREGIÃO DO CARIRI CEARENSE}

Assim, no que se refere à capacidade de geração de emprego da agropecuária cearense, pode ser ela observada a partir da tabela 1 , em que se utilizou a média aritmética do número absoluto de pessoas empregadas formalmente no setor agropecuário nos anos 2005 e 2006 e nos anos 2012 e 2013 para cada microrregião do Ceará. A partir dessas médias, calculou-se o percentual em relação ao total de empregos formais. Além disso, apresenta-se a variação, com relação ao emprego formal, entre 2005/2006 e 2012/2013.

Conforme os dados, das 33 microrregiões cearenses, apenas duas, Baixo Jaguaribe e Fortaleza, tiveram o maior número de formalização empregatícia do setor agropecuário em ambos os anos estudados - a primeira microrregião, embora represente $25,53 \%$ da formalização empregatícia em 2005/2006 e 18,40 \% em 2012/2013, reduziu o número de postos de trabalho formal em 14,15\%; a segunda, a de Fortaleza, apresentou 24,35\% e 22,10\% dos trabalhadores formais em 2005/2006 e 2012/2013, respectivamente.

Tabela 01 - Emprego Formal na agropecuária cearense, segundo as microrregiões do Ceará - 2005/2006 e 2012/2013.

\begin{tabular}{|c|c|c|c|c|c|}
\hline \multirow{2}{*}{ Microrregiões do Ceará } & \multicolumn{2}{|c|}{$2005 / 2006$} & \multicolumn{2}{|c|}{$2012 / 2013$} & \multirow{2}{*}{$\%$} \\
\hline & $\mathrm{ABS}$ & $\%$ & $\mathrm{ABS}$ & $\%$ & \\
\hline Litoral de Camocim e Acaraú & 621 & 5,91 & 798 & 6,38 & 28,53 \\
\hline Ibiapaba & 499 & 4,76 & 748 & 5,99 & 49,90 \\
\hline Coreaú & 2 & 0,02 & 7 & 0,06 & 250,00 \\
\hline Meruoca & 5 & 0,04 & 1 & 0,01 & $-77,78$ \\
\hline Sobral & 85 & 0,81 & 45 & 0,36 & $-46,75$ \\
\hline $\mathrm{Ipu}$ & 2 & 0,02 & 3 & 0,02 & 25,00 \\
\hline Santa Quitéria & 9 & 0,08 & 4 & 0,03 & $-58,82$ \\
\hline Itapipoca & 287 & 2,74 & 264 & 2,11 & $-8,01$ \\
\hline Baixo Curu & 338 & 3,22 & 466 & 3,73 & 37,87 \\
\hline Uruburetama & 50 & 0,48 & 64 & 0,51 & 27,00 \\
\hline Médio Curu & 73 & 0,69 & 128 & 1,02 & 76,55 \\
\hline Canindé & 67 & 0,64 & 31 & 0,24 & $-54,48$ \\
\hline Baturité & 89 & 0,84 & 161 & 1,28 & 81,36 \\
\hline Chorozinho & 35 & 0,33 & 265 & 2,12 & 657,14 \\
\hline Cascavel & 905 & 8,62 & 932 & 7,45 & 2,99 \\
\hline Fortaleza & 2.555 & 24,35 & 2.762 & 22,10 & 8,08 \\
\hline Pacajus & 329 & 3,13 & 537 & 4,29 & 63,32 \\
\hline Sertão de Crateús & 1 & 0,01 & 1 & 0,01 & 0,00 \\
\hline Sertão de Quixeramobim & 201 & 1,91 & 349 & 2,79 & 73,82 \\
\hline Sertão de Inhamuns & 8 & 0,07 & 11 & 0,08 & 40,00 \\
\hline Sertão de Senador Pompeu & 27 & 0,26 & 49 & 0,39 & 79,63 \\
\hline Litoral de Aracati & 1.388 & 13,22 & 2.080 & 16,64 & 49,87 \\
\hline Baixo Jaguaribe & 2.679 & 25,53 & 2.300 & 18,40 & $-14,15$ \\
\hline Médio Jaguaribe & 1 & 0,00 & 37 & 0,29 & 7200,00 \\
\hline Serra do pereiro & 3 & 0,02 & 1 & 0,00 & $-80,00$ \\
\hline Iguatu & 50 & 0,47 & 104 & 0,83 & 109,09 \\
\hline Várzea alegre & 6 & 0,05 & 5 & 0,04 & $-9,09$ \\
\hline Lavras da mangabeira & 2 & 0,02 & 2 & 0,02 & 0,00 \\
\hline Chapada do Araripe & 0 & 0,00 & 2 & 0,01 & 2,00 \\
\hline Caririaçu & 0 & 0,00 & 1 & 0,00 & 1,00 \\
\hline Barro & 1 & 0,01 & 12 & 0,09 & 1050,00 \\
\hline Cariri & 166 & 1,58 & 316 & 2,52 & 90,06 \\
\hline Brejo santo & 18 & 0,17 & 22 & 0,18 & 25,71 \\
\hline Total & 10.494 & 100,00 & 12.498 & 100,00 & 19,10 \\
\hline
\end{tabular}

Fonte: Elaborado pelos autores a partir de dados da RAIS/TEM

DRd - Desenvolvimento Regional em debate (ISSNe 2237-9029) 
É importante observar o comportamento da microrregião do Cariri, que vem ganhando espaço na geração de empregos nesse setor, embora a sua participação ainda seja modesta, se comparada às microrregiões do Baixo Jaguaribe, Litoral de Aracati e Fortaleza. Os dados da tabela 1 mostram que, no primeiro período, o número de empregos formais era de 166 (1,58\%), o qual passa no segundo período para 316 (2,52\%), com variação de $90,06 \%$. Tal incremento pode ser justificado pelas conquistas de avanços tecnológicos na agropecuária.

Além disso, com relação às demais microrregiões, embora algumas tenham aumentado expressivamente o número de empregos formais, outras apresentaram parcela ínfima numa prova de pouco dinamismo. No geral, todas as microrregiões elevaram o número de empregos formais na agropecuária, em, aproximadamente, $19,10 \%$ nos períodos em questão. O que mostra a capacidade de geração de empregos do setor agropecuário cearense, não obstante a da concentração em algumas microrregiões explicável por fatores climáticos, locacionais, hídricos e maior atuação de projetos de desenvolvimento rural.

\section{INDICADORES DE CRIAÇÃO E DESTRUIÇÃO DE POSTOS DE TRABALHO NA MICRORREGIÃO DO CARIRI}

Apesar da capacidade de geração de emprego do setor agropecuário cearense, e consequentemente da importância desse fator para o desenvolvimento rural, faz-se necessária a análise das características socioeconômicas e demográficas dos postos de trabalho gerados.

Na tabela 2, a TC (Taxa de Criação) foi determinada por meio da razão entre o número de trabalhadores admitidos e a média do total de empregos formais nos anos 2006 e 2013. A mesma metodologia foi aplicada à TD (Taxa de Destruição), sendo que esta é o resultado da razão entre o número de funcionários demitidos e a média do total de empregos formais nos anos 2006 e 2013. No tocante à TCL (Taxa de Criação Líquida), foi ela obtida por meio da diferença entre a TC e a TD no mesmo período de tempo em que se encontram estas duas últimas taxas. 
Tabela 02 - Taxa de Criação Líquida do Emprego formal, segundo as microrregiões do Ceará - 2006/2012

\begin{tabular}{|c|c|c|c|c|c|c|}
\hline \multirow{2}{*}{ Microrregiões do Ceará } & \multicolumn{3}{|c|}{2006} & \multicolumn{3}{|c|}{2013} \\
\hline & $\mathrm{TC}$ & TD & TC Líquida & $\mathrm{TC}$ & TD & TC Líquida \\
\hline Litoral de Camocim e Acaraú & 0,54 & 0,39 & 0,15 & 0,40 & 0,53 & $-0,13$ \\
\hline Ibiapaba & 0,20 & 0,13 & 0,07 & 0,49 & 0,33 & 0,17 \\
\hline Coreaú & 0,33 & 0,33 & 0,00 & 1,05 & 0,57 & 0,48 \\
\hline Meruoca & 0,00 & 0,00 & 0,00 & 0,00 & 0,00 & 0,00 \\
\hline Sobral & 0,77 & 0,92 & $-0,16$ & 0,53 & 0,52 & 0,01 \\
\hline $\mathrm{Ipu}$ & 0,00 & 0,67 & $-0,67$ & 1,60 & 0,53 & 1,07 \\
\hline Santa Quitéria & 0,31 & 0,39 & $-0,08$ & 0,00 & 0,19 & $-0,19$ \\
\hline Itapipoca & 0,07 & 0,20 & $-0,13$ & 0,20 & 0,76 & $-0,55$ \\
\hline Baixo Curu & 0,77 & 0,54 & 0,23 & 0,92 & 0,94 & $-0,02$ \\
\hline Uruburetama & 0,41 & 0,33 & 0,08 & 0,26 & 0,39 & $-0,13$ \\
\hline Médio Curu & 5,16 & 4,38 & 0,78 & 0,32 & 0,44 & $-0,13$ \\
\hline Canindé & 0,21 & 0,10 & 0,11 & 0,37 & 0,44 & $-0,07$ \\
\hline Baturité & 0,05 & 0,48 & $-0,43$ & 0,34 & 0,38 & $-0,04$ \\
\hline Chorozinho & 0,34 & 0,53 & $-0,19$ & 0,08 & 0,13 & $-0,05$ \\
\hline Cascavel & 0,27 & 0,33 & $-0,06$ & 0,58 & 0,68 & $-0,10$ \\
\hline Fortaleza & 0,38 & 0,41 & $-0,03$ & 0,55 & 0,49 & 0,06 \\
\hline Pacajus & 0,19 & 0,18 & 0,02 & 0,56 & 0,52 & 0,04 \\
\hline Sertão de Crateús & 3,33 & 6,00 & $-2,67$ & 2,00 & 0,67 & 1,33 \\
\hline Sertão de Quixeramobim & 0,25 & 0,18 & 0,07 & 0,46 & 0,37 & 0,08 \\
\hline Sertão de Inhamuns & 0,00 & 0,00 & 0,00 & 0,13 & 0,25 & $-0,13$ \\
\hline Sertão de Senador Pompeu & 0,22 & 0,00 & 0,22 & 0,37 & 0,41 & $-0,04$ \\
\hline Litoral de Aracati & 1,15 & 0,87 & 0,28 & 1,27 & 1,05 & 0,22 \\
\hline Baixo Jaguaribe & 0,82 & 0,71 & 0,11 & 1,22 & 1,12 & 0,10 \\
\hline Médio Jaguaribe & 2,67 & 2,67 & 0,00 & 0,40 & 0,31 & 0,09 \\
\hline Serra do Pereiro & 0,00 & 0,00 & 0,00 & 0,00 & 0,00 & 0,00 \\
\hline Iguatu & 0,46 & 0,48 & $-0,03$ & 0,79 & 0,59 & 0,21 \\
\hline Várzea alegre & 0,00 & 0,12 & $-0,12$ & 0,00 & 0,13 & $-0,13$ \\
\hline Lavras da mangabeira & 0,00 & 0,00 & 0,00 & 0,00 & 0,00 & 0,00 \\
\hline Chapada do Araripe & 0,00 & 0,00 & 0,00 & 0,00 & 0,00 & 0,00 \\
\hline Caririaçu & 0,00 & 0,00 & 0,00 & 1,33 & 0,00 & 1,33 \\
\hline Barro & 1,33 & 0,00 & 1,33 & 0,52 & 0,46 & 0,06 \\
\hline Cariri & 0,72 & 0,55 & 0,18 & 0,72 & 0,47 & 0,25 \\
\hline Brejo santo & 0,04 & 0,11 & $-0,08$ & 0,15 & 0,21 & $-0,06$ \\
\hline Total & 0,62 & 0,54 & 0,07 & 0,77 & 0,71 & 0,06 \\
\hline
\end{tabular}

Fonte: Elaborado pelos autores a partir de dados da RAIS/MTE.

De acordo com a tabela 2, no primeiro período, a microrregião do Cariri teve uma TC de 0,48 , enquanto a sua TD foi de 0,36 , o que conferiu uma TCL de 0,12 . É importante ressaltar que embora a sua TCL tenha ficado bem abaixo das obtidas pelas regiões de Barro, Médio Curu e Litoral de Aracati, ainda se fez expressiva, em virtude do alto número de microrregiões cearenses com taxas nulas e negativas. No segundo período, a microrregião em apreço elevou a sua TCL para 0,17 , em decorrência da TC de 0,50 e da TD de 0,33 . Trata-se de resultado positivo na geração de empregos formais, frente ao elevado número de regiões que também ostentaram nesse ano taxas nulas e negativas.

Conforme os dados, no ano 2006, as microrregiões do Médio Curu e do Sertão de Crateús foram as de maiores TC's $(3,58$ e 1,67) e TD's $(3,04$ e 3,00) de postos de trabalho formal, sendo que a TCL da segunda foi negativa $(-1,33)$. No ano de 2013 , a microrregião do Sertão de Crateús continuou com a maior TC $(2,00)$, só que desta feita com menor TD $(0,67)$, o que consequentemente the garantiu maior TCL $(1,33)$ de empregos formais. Já a microrregião do Médio Curu perdeu espaço para a de Coreaú, agora uma TC de 1,29 e uma TD de 0,71 , o que lhe deu aumento na TCL (de 0,00 para 0,59 ) em relação ao ano anterior. 
Apesar de a microrregião do Médio Curu, no ano 2006, ter obtido uma TCL positiva $(0,54)$, no período seguinte declinou $(-0,10)$, decorrente da diminuição de sua TC (de 3,58 para 0,26), bem como de sua TD (de 3,04 para 0,36), porém ainda se situando esta última em patamar superior ao da primeira.

Sabendo-se que cada microrregião constitui um caso específico, procurou-se destacar aqui apenas aquelas com variações mais expressivas, de forma que, dentre as demais, algumas evoluíram paulatinamente, como é o caso da microrregião do Ipu, enquanto outras, já com baixa participação na criação de empregos formais, mantiveram a mesma situação, demonstrando que a dinâmica do emprego formal no setor se concentra nas regiões com fatores favoráveis ao desenvolvimento da atividade, dificultando a absorção da PEA rural para as outras microrregiões, que é o caso de Santa Quitéria e de Itapipoca.

Tabela 03 - Taxa de Criação Líquida do Emprego formal na agropecuária da microrregião do Cariri, segundo o tamanho do estabelecimento - 2006/2013.

\begin{tabular}{l|c|c|c|cccc}
\hline \multirow{2}{*}{ Tamanho do estabelecimento } & \multicolumn{3}{c|}{2006} & \multicolumn{4}{c}{2013} \\
\cline { 2 - 8 } & TC & TD & TC Líquida & TC & TD & TC Líquida \\
\hline Micro & 0,66 & 0,68 & $-0,02$ & 0,77 & 0,31 & 0,46 \\
Pequeno & 0,79 & 0,22 & 0,57 & 0,26 & 0,35 & $-0,09$ \\
Médio & 0,13 & 0,04 & 0,09 & 0,54 & 0,32 & 0,22 & 0,09 \\
Grande & 0,00 & 0,00 & 0,00 & 0,00 & 0,00 & 0,00 & 0,17 \\
\hline Total & 0,48 & 0,36 & 0,12 & 0,50 & 0,33 & 0,17 \\
\hline
\end{tabular}

Fonte: Elaborado pelos autores a partir de dados da RAIS/CAGED/MTE.

Os dados da tabela 3 mostram a TCL do emprego formal na agropecuária da microrregião do Cariri segundo o tamanho do estabelecimento. Pode-se aí ver, que, no ano de 2006 , a maior TC de postos de trabalho $(0,79)$ ocorreu no pequeno estabelecimento. No ano de 2013 , a maior TC $(0,77)$ passou a pertencer ao micro, seguido dos médios estabelecimentos $(0,54)$.

No que se refere à TD, tem-se que a maior redução dos postos de trabalho $(0,68)$ ocorreu, no ano de 2006, no microestabelecimento. Em 2013, a TD mais significativa $(0,35)$ ficou com o pequeno estabelecimento seguido do médio $(0,32)$.

Agora quanto à TCL, no ano de 2006, ela apresentou melhor desempenho no pequeno estabelecimento (0.57), tendo ocorrido seu maior declínio no micro (-0,02). Em 2013, ocorreu o inverso: aumento de postos de trabalho no microestabelecimento $(0,46)$ e diminuição no pequeno $(-0,09)$. Houve, como se pode observar, uma troca de papéis entre o micro e pequeno estabelecimento no que concerne à geração de empregos formais. Tal fenômeno pode decorrer do aumento na capacidade de geração de emprego no do menor estabelecimento, fazendo-o a se classificar para o pequeno estabelecimento. É importante ressaltar também a postura nula e constante dos grandes estabelecimentos da microrregião em estudo.

A dinâmica do micro e pequeno estabelecimento na criação de empregos pode estar associada à baixa produtividade e ao baixo progresso técnico. Não obstante a expressão mínima no total da produção desses estabelecimentos, os mesmos são os que possuem a maior população agrícola (SAKAMOTO; MAIA, 2012). Eles também desempenham a função de abastecimento do mercado interno, enquanto a produção voltada para o mercado externo se dá nos grandes estabelecimentos à custa de altos índices de mecanização e, consequentemente, baixo número de ocupações (FERREIRA et al., 2006). 
Quanto ao sexo do trabalhador, conforme a tabela 4 houve uma maior capacidade do sexo masculino quanto à taxa de criação em ambos os anos, o qual levou a apresentar uma TCL de 0,15 em 2006 e de 0,19 em 2013; enquanto, a TCL do sexo feminino foi negativa nos dois períodos em apreço por apresentar TC's superior as TD's.

Tabela 04 - Taxa de Criação Líquida do Emprego formal na agropecuária do Cariri, segundo o sexo do trabalhador $2006 / 2012$.

\begin{tabular}{l|c|c|c|c|c|c}
\hline \multirow{2}{*}{ Sexo do Trabalhador } & \multicolumn{4}{c|}{2006} & \multicolumn{3}{c}{2013} \\
\cline { 2 - 8 } & TC & TD & TC Líquida & TC & TD & TC Líquida \\
\hline Masculino & 0,54 & 0,39 & 0,15 & 0,53 & 0,34 & 0,19 \\
Feminino & 0,14 & 0,19 & $-0,05$ & 0,19 & 0,24 & $-0,04$ \\
\hline Total & 0,48 & 0,36 & 0,12 & 0,50 & 0,33 & 0,17 \\
\hline
\end{tabular}

Fonte: Elaborado pelos autores a partir de dados da RAIS/CAGED/MTE.

A baixa participação das mulheres no mercado de trabalho agropecuário é comumente registrada em estudos que analisam o fenômeno (OLIVEIRA, 2011; SANTOS et al., 2012), isso por ser a atividade intensiva e demandar maior força física (SILVA FILHO; SILVA, 2011). Além do mais, o estudo de Kageyama (2003) observa que, no Nordeste, a maior absorção da mão de obra feminina do meio rural ocorre no setor doméstico.

De acordo com a tabela 5 , relativamente à faixa etária de 50 a 64 anos de idade, a TD $(1,07)$ no ano de 2006 foi a mais elevada; mas, permaneceu inferior à TC $(1,24)$, contribuindo para um saldo positivo da TCL em 0,18. O mesmo caso ocorreu em $2013 \mathrm{com}$ a faixa etária de 18 a 24 anos de idade: a TC $(0,81)$ foi superior à TD $(0,54)$, ainda que esta última tenha exibido, dentre as demais, um forte declínio em relação aos empregos formais. Vale ressaltar que a faixa etária dos 65 anos de idade ou mais no ano 2006 apresentou TCL nula. É que a criação e destruição de postos de trabalho se der na mesma proporção, ou seja, TC da ordem de 0,67 ; o mesmo ocorreu com a TD. No o ano de 2013, a TC foi nula.

Tabela 05 - Taxa de Criação Líquida do Emprego formal na agropecuária da microrregião do Cariri, segundo a Faixa Etária do trabalhador - 2006/2013.

\begin{tabular}{l|c|c|c|c|c|c}
\hline \multirow{2}{*}{ Faixa Etária } & \multicolumn{3}{c|}{2006} & \multicolumn{2}{c}{2013} \\
\cline { 2 - 7 } & TC & TD & TC Líquida & TC & TD & TC Líquida \\
\hline Até 17 & 2 & 0 & 2 & 2,4 & 0,4 & 2 \\
18 a 24 & 0,39 & 0,32 & 0,07 & 0,81 & 0,54 & 0,27 \\
25 a 29 & 0,31 & 0,22 & 0,08 & 0,50 & 0,35 & 0,15 \\
30 a 39 & 0,45 & 0,31 & 0,14 & 0,39 & 0,29 & 0,10 \\
40 a 49 & 0,78 & 0,59 & 0,20 & 0,34 & 0,19 & 0,15 \\
50 a 64 & 1,24 & 1,07 & 0,18 & 0,39 & 0,09 & 0,30 \\
65 ou mais & 0,67 & 0,67 & 0,00 & 0,00 & 0,00 & 0,00 \\
\hline Total & 0,48 & 0,36 & 0,12 & 0,50 & 0,33 & 0,17 \\
\hline
\end{tabular}

Fonte: Elaborado pelos autores a partir de dados da RAIS/CAGED/MTE.

Com exceção da faixa etária de até 17 anos, a dinâmica do emprego formal na microrregião do Cariri mostrou que, no primeiro ano em estudo, as maiores faixas etárias obtiveram expressivas TCL's (associadas a altas TC e TD). Ou seja, a mão de obra jovem tinha pouco espaço na agropecuária. Isso pode ser justificado pelas migrações de trabalhadores para outros setores da economia local, a citar, o desempenho da indústria calçadista da região. 
Já, no segundo ano, apesar da variação positiva nas TCL's nas faixas de 18 a 29 anos, ainda quem se destaca com a maior TCL dada a menor TD, com exceção da faixa de até 17 anos, é a força de trabalho de 50 a 64 anos. A última faixa etária de 65 anos ou mais não teve TC e TD, o que pode ser justificado pela expansão das aposentadorias no meio rural, sobretudo, no Nordeste, tal como referem os estudos de Kageyama (2003), Ferreira et al. (2006) e Campolina et al. (2009).

Outra análise que requer atenção é a do nível de escolaridade dos trabalhadores. Apesar das melhorias, o Nordeste ainda possui expressivo contingente da PEA rural com baixo nível de escolaridade (FERREIRA et al., 2006). Para Silva Filho e Silva (2011), essa é uma das características intrínsecas do trabalho/intensivo da agropecuária da região. Esse cenário é confirmado para o trabalhador formal do Cariri através da tabela 6 , onde se vê que, apesar da evolução no nível de escolaridade do trabalhador, ainda é nas primeiras faixas que se concentram as maiores taxas de criação de emprego.

Tabela 06 - Taxa de Criação Líquida do Emprego formal na agropecuária da microrregião do Cariri, segundo o Nível de Escolaridade - 2006/2013.

\begin{tabular}{|c|c|c|c|c|c|c|}
\hline \multirow{2}{*}{ Nível de Escolaridade } & \multicolumn{3}{|c|}{2006} & \multicolumn{3}{|c|}{2013} \\
\hline & TC & TD & TC Líquido & $\mathrm{TC}$ & TD & TC Líquida \\
\hline Analfabeto & 3,61 & 1,46 & 2,15 & 0,65 & 0,38 & 0,27 \\
\hline Até $5^{\mathrm{a}}$ Incompleto & 1,48 & 1,25 & 0,23 & 1,30 & 0,30 & 1,01 \\
\hline $5^{\text {a }}$ Completo Fundamental & 0,38 & 0,19 & 0,19 & 0,33 & 0,27 & 0,05 \\
\hline $6^{a}$ a $9^{a}$ Fundamental & 0,00 & 0,16 & $-0,16$ & 0,40 & 0,37 & 0,04 \\
\hline Fundamental Completo & 0,03 & 0,08 & $-0,06$ & 0,48 & 0,41 & 0,06 \\
\hline Médio Incompleto & 0,17 & 0,43 & $-0,26$ & 0,20 & 0,46 & $-0,26$ \\
\hline Médio Completo & 0,24 & 0,31 & $-0,08$ & 0,29 & 0,22 & 0,07 \\
\hline Superior Incompleto & 0,86 & 0,00 & 0,86 & 0,00 & 0,17 & $-0,17$ \\
\hline Superior Completo & 0,67 & 0,17 & 0,50 & 0,53 & 0,18 & 0,35 \\
\hline Mestrado & 0,00 & 0,00 & 0,00 & 0,00 & 0,00 & 0,00 \\
\hline Doutorado & 0,00 & 0,00 & 0,00 & 0,00 & 0,00 & 0,00 \\
\hline Total & 0,48 & 0,36 & 0,12 & 0,50 & 0,33 & 0,17 \\
\hline
\end{tabular}

Fonte: Elaborado pelos autores a partir de dados da RAIS/CAGEG/MTE.

$\mathrm{Na}$ análise da tabela 6 , foram considerados apenas os valores mais significativos, em relação ao comportamento das TC, TD e TCL do emprego formal, conforme o nível de escolaridade nos anos 2006 e 2013. No ano 2006, a maior parte dos empregos formais criados $(\mathrm{TC}=3,61)$ na agropecuária destinou-se às pessoas tidas como analfabetas, bem como a maior TD $(1,46)$, porém esta última foi bem inferior à primeira, ocasionando, por conseguinte, a maior TCL $(2,15)$ do emprego formal neste setor. A menor TCL de postos de trabalho formal $(-0,26)$, no mesmo período, incidiu no nível escolar médio incompleto, devido à TD $(0,43)$ que foi maior que a TC $(0,17)$.

Já no ano de 2013, a maior TC $(1,30)$ pertenceu ao nível escolar de até a $5^{\text {a }}$ série incompleta, bem como a maior TCL $(1,00)$, a qual aumentou consideravelmente com relação ao ano anterior. Enquanto isso as faixas de Mestrado e Doutorado mantiveram-se nulas. A maior TD $(0,46)$ de empregos formais no ano 2013 permaneceu no nível médio incompleto, embora a TC e a TD tenham aumentado em relação ao ano anterior; esta última (TD) se manteve maior do que a primeira (TC), o que resultou na maior redução da TCL $(-0,26)$, dentre os demais níveis de escolaridade. 
Reduzida aos baixos níveis de escolaridade dos empregados formais na agropecuária da microrregião do Cariri é de se esperar a baixa remuneração auferida por esses trabalhadores, visto que, conforme Ferreira et al. (2006), o nível de instrução tem forte relação com o grau de rendimento, afirmação essa, baseadas nas teorias de capital humano.

Tabela 07 - Taxa de Criação Líquida do Emprego formal na agropecuária da microrregião do Cariri, segundo a Faixa de Remuneração do trabalhador - 2006/2013.

\begin{tabular}{l|c|c|c|c|c|c}
\hline \multicolumn{1}{c}{ Faixa de Remuneração } & \multicolumn{3}{c|}{2006} & \multicolumn{2}{c}{2013} \\
\cline { 2 - 7 } & TC & TD & TC Líquida & TC & TD & TC Líquida \\
\hline Até 1 SM & 1,06 & 0,64 & 0,42 & 0,86 & 0,48 & 0,38 \\
Mais de 1 a 2 SM & 0,08 & 0,11 & $-0,03$ & 0,26 & 0,22 & 0,04 \\
Mais de 2 a 4 SM & 0,05 & 0,27 & $-0,22$ & 0,25 & 0,25 & 0,00 \\
Mais de 4 a 7 SM & 0,44 & 0,44 & 0,00 & 0,75 & 0,25 & 0,50 \\
Mais de 7 a 15 SM & 0,00 & 0,00 & 0,00 & 2,00 & 0,00 & 2,00 \\
Mais de 15 SM & 0,00 & 0,00 & 0,00 & 0,00 & 0,00 & 0,00 \\
\{ñ class & 0,00 & 0,00 & 0,00 & 0,00 & 0,00 & 0,00 \\
\hline Total & 0,48 & 0,36 & 0,12 & 0,50 & 0,33 & 0,17 \\
\hline
\end{tabular}

Fonte: Elaborado pelos autores a partir de dados RAIS/CAGED/MTE.

De acordo com a tabela 07, a TCL de emprego formal na agropecuária, segundo a faixa de remuneração, no ano de 2006, apresentou seu maior valor $(0,42)$ quando a faixa de remuneração foi até 1 salário mínimo. Já seu menor valor $(-0,22)$ ocorreu quando a faixa de remuneração ficou de 2 até 4 salários mínimos. Para o ano de 2013, a maior TCL $(2,00)$ se deu na faixa de remuneração de mais de 7 até 15 salários mínimos, enquanto a menor $(0,00)$ figurou em três faixas, a saber: as de mais de 2 até 4 e de mais de 15 salários mínimos. Merece destaque também o caso em que a TC foi estatisticamente igual à TD, não havendo, portanto, TCL. São exemplos deste caso as faixas de remuneração de mais de 4 até 7 salários mínimos em 2006, e de mais de 2 até 4 salários mínimos em 2013. Houve também o caso das faixas de remuneração de mais de 15 salários mínimos e de não classificadas, nas quais todas as taxas foram iguais a $0,00 \mathrm{em}$ ambos os anos.

\section{CONSIDERAÇÕES FINAIS}

O artigo tem como objetivo analisar o saldo de vagas nos postos de trabalho formais da microrregião do Cariri cearense, segundo as características demográficas e socioeconômicas dos trabalhadores, nos anos de 2006 e 2013. Metodologicamente, utiliza-se o método de cálculo da Taxa de Criação Líquida (TCL) de empregos formais, construído com dados do Ministério do Trabalho (MTE) - Relação Anual de Informações Sociais (RAIS) e Cadastro Geral de Empregados e Desempregados (CAGED).

Os resultados mostraram que, embora as microrregiões Baixo Jaguaribe e Fortaleza detenham o maior número absoluto de pessoas empregadas formalmente no setor agropecuário em ambos os anos (2005 e 2006, e nos anos 2012 e 2013), ainda que a primeira se tenha reduzido simploriamente quando comparados os anos em estudo, elas não mostraram bons resultados no que concerne à taxa de criação líquida do emprego formal. Já outras que detinham menor número de empregados, em termos absolutos, comparadas com as já citadas,

DRd - Desenvolvimento Regional em debate (ISSNe 2237-9029) 
conseguiram resultados mais satisfatórios, tais como Médio Curu e Barro, em 2006, e Sertão de Crateús e Caririaçu, em 2013, na criação líquida de emprego nos períodos em estudo.

Quanto à taxa de criação líquida de trabalhos formalizados na microrregião do Cariri, no tocante ao tamanho do estabelecimento, ao sexo, à faixa etária, ao nível de escolaridade e à faixa salarial do trabalhador, observou-se para o ano de 2006 os seguintes resultados: I) o pequeno estabelecimento demonstrou maior capacidade de absorção da PEA rural no período; II) ainda prevalece o trabalhador do sexo masculino em comparação com seu sexo feminino; III) foi registrada a maior TCL na faixa etária de até 17 anos de idade; IV) prevaleceu com maior taxa o analfabeto; e V) a taxa líquida de emprego formal mais elevada foi apontada na faixa de remuneração de até 1 salário mínimo. Interligando todos os pontos para o ano acima (2006), infere-se que a taxa líquida de criação de emprego formal na agropecuária se realizou nos pequenos estabelecimentos, com mão de obra principalmente masculina, tendo a maioria até 17 anos de idade, com nível escolar de analfabeto e remuneração de até 1 salário mínimo.

Já para o ano de 2013, as informações obtidas foram: I) o microestabelecimento foi o responsável pela maior absorção da mão de obra rural; II) o trabalhador do sexo masculino continua dominando as ocupações no setor; III) a maior TCL de empregos formais mantevese na faixa etária de até 17 anos; IV) prevaleceu a maior taxa no nível escolar até $5^{\circ}$ ano incompleto; e V) foi na faixa na faixa de 4 a 7 SM que a taxa foi mais elevada, embora seja seguida pela menor faixa de remuneração, até $1 \mathrm{SM}$.

Portanto, evidencia-se a precarização dos postos de trabalho para o emprego formal na agropecuária da região em estudo, implicando na permanência da situação de pobreza para a PEA rural. Ademais, de acordo com a literatura, há uma tendência para que o setor agropecuário absorva cada vez menos mão de obra. Dado a baixo nível de escolaridade nessa região, faz-se necessário a atuação do Estado com o fito de profissionalizar os trabalhadores rurais para que esses sejam adequadamente absorvidos pelos demais setores da economia.

\section{REFERÊNCIAS}

BAGOLIN, I. P.; STÚLP, V. J. Evolução da mão de obra ocupada no setor agropecuário do Rio Grande do Sul. Revista de Economia e Agronegócio, v. 10, p. 51-70, 2012.

BALSADI, O. V. Evolução das ocupações e do emprego na agropecuária do Centro-Oeste brasileiro no período 2001-05. Informações Econômicas, São Paulo, v. 39, p. 32-40, 2009.

BALSADI, O. V. Evolução as ocupações e do emprego na agricultura brasileira no período 1992-2006. In: BUAINAIN, A. M.; DEDECCA, C. S. (Org.). Emprego e trabalho na agricultura brasileira. Brasília: IICA, 2008, p.93-132.

BALSADI, O. V. O mercado de trabalho assalariado na agricultura brasileira. Economia e planejamento: teses e pesquisas. São Paulo: Hucitec, 2008.

BALSAN, R. Impactos decorrentes da modernização da agricultura brasileira. Revista de Geografia Agrária, v. 1, n. 2, p. 123-151, ago. 2006. 
BAUINAIN, A. M.; DEDECA, C. S. Introdução: emprego e trabalho na agricultura brasileira. In: BUAINAIN, A. M.; DEDECCA, C. S. (Org.). Emprego e trabalho na agricultura brasileira. Brasília: IICA, 2008, p. 19-60.

BRASIL, Ministério do Trabalho e do Emprego. Cadastro Geral de Empregados e Desempregados - CAGED, 2013.

BRASIL, Ministério do Trabalho e do Emprego. Relação Anual de Informações Sociais, 2013.

CAMPOLINA, B.; SILVEIRA, F. G.; MAGALHÃES, L. C. G. O mercado de trabalho rural: evolução recente, composição da renda e dimensão regional. Texto para discursão. Rio de Janeiro: IPEA, mar. 2009.

DEDECCA, C. S. (Org.). Emprego e trabalho na agricultura brasileira. Brasília: IICA, 2008.

DEL GROSSI, M. E.; Dinâmicas dos Mercados de Trabalho no Campo. In: MIRANDA, Carlos; TIBÚRCIO, Breno (Org.). Emprego e trabalho na agricultura brasileira. Brasília: IICA, 2008, p. 135-155.

FERREIRA, B. et al. Ocupações Agrícolas e não-agrícolas: Trajetória e rendimentos no meio rural brasileiro. In: NEGRI, J. A; NEGRI, F. COELHO, D. (Org.). Brasil: o estado de uma nação, Rio de Janeiro: IPEA, 2006, p.445-488.

GIRARD, E. P. O rural e o urbano: é possível uma tipologia?. Disponível em:

$<$ http://www.geo.uel.br/didatico/omar/modulo_b/a12.pdf $>$. Acesso em: 05 jun. 2018.

KAGEYAMA, A. Mudanças no trabalho rural no Brasil, 1992-2002. Agricultura São Paulo, São Paulo, v. 51, n. 2, p. 71-84, jul./dez. 2004.

MARTIN, P. The study of rural labor markets. Western Journal of Agricultural Economics, v. 1, n. 1, p. 56-63, jun. 1977.

MDUMA, K.K.; WOBST, P. Determinants of rural labor market participation in Africall. African Studies Quarterly, v. 8, n. 2, pp. 32-47, 2005.

MENDONÇA, M. R.; RIBEIRO, D. D.; THOMAZ JUNIOR, A. A modernização da agricultura e os impactos sobre o trabalho. Revista Electrónica de Geografía y Ciencias Sociales, v. 119, n. 44, ago. 2002.

OLIVEIRA, F. C. R. Mercado de trabalho assalariado na cana-de-açúcar e em outras atividades Agropecuárias, de 1992 a 2007. 48 Congresso SOBER. Anais... Campo Grande MS, 2010.

SAKAMOTO, C. S.; MAIA, G. A. Dinâmica do mercado de trabalho agrícola e impactos sobre a distribuição de rendimentos nos anos 2000. ABET, v. 11, n.2, jul./dez. 2012. 
SANTOS, F. V. D.; SILVA FILHO, L. A.; LIMA, M. M. F. Evolução do Emprego Formal Agropecuário na Bahia - 2000/2010. Revista Conjuntura e Planejamento, Salvador, n.177, p. 28-39, out./dez. 2012.

SHENG, L. Rural labor force emigration on the impact and effect of macro-economy in China. 2008. Disponível em: <http://www.stats.gov.cn/english/icas/papers/ P020071114297555473181.pdf>. Acesso em: 05 jun. 2018.

SILVA, J. G. O novo rural brasileiro. Revista Nova economia, Belo horizonte, v. 7, n. 1, p. 43-81, maio 1997.

SILVA FILHO, L. A.; SILVA, J. L. M. Evolução do Emprego Formal na Agropecuária do Nordeste Brasileiro - 1999-2009. In: CONGRESSO SOBER; 49. Anais... Belo Horizonte, 2011.

STANEF, M. F. Increasing labor market participation and reducing structural unemployment in rural and urban areas of Europe: case study: Romania. Theoretical and Applied Economics. v. 3, n. 568, p. 149-156, 2012.

Artigo recebido em: 06/03/2018

Artigo aprovado em: 21/06/2018 